\title{
«¿Entiendes lo que estás leyendo?»(Hch 8,30) Acerca de la traducción de la Biblia de la Iglesia en América
}

\author{
SANTIAGO SILVA RETAMALES \\ Centro Bíblico Pastoral para América Latina, \\ CEBIPAL - CELAM (Colombia) \\ ssilva@episcopado.cl
}

\begin{abstract}
Resumen
El presente artículo tiene como objetivo presentar los criterios utilizados para la traducción de la Sagrada Escritura llamada Biblia de la Iglesia en América (BIA). Lo que se busca responder es ¿Qué hermenéutica está en la base de esta nueva traducción promovida por el Consejo Episcopal Latinoamericano (CELAM)?. Estas páginas quieren destacar que la Sagrada Escritura no es un libro cualquiera sino que se trata de la expresión literaria de la religión de un pueblo. Por otra parte, el tema de este artículo puede ayudar al lector a evaluar la calidad de las traducciones bíblicas que circulan en la actualidad y a determinar los criterios que permitan saber cuándo usar una traducción y cuándo emplear otra.
\end{abstract}

Palabras claves: hermenéutica, Sagrada Escritura, traducción, Consejo Episcopal Latinoamericano (CELAM).

\section{«Do you understand what you read?» (Acts 8,30) About the translation of the Bible of the Church in America}

\begin{abstract}
This article aims to present the criteria used for the translation of the Bible called the Holy Scriptures of the Church in America (BIA). We seek to answer the question: What is the basis hermeneutics of this new translation sponsored by the Latin American Episcopal Council (CELAM)? These pages want to emphasize that Scripture is not just any book, but it is the literary expression of the religion of a people. Moreover, the theme of this article can belp the reader to evaluate the quality of biblical translations currently circulating and the criteria for determining when to use a translation or another.
\end{abstract}

Key words: hermeneutic, Bible, translation, Latiamerican Bishop's Council (CELAM).

Obispo auxiliar de la diócesis de Valparaíso. Licenciado en Teología Dogmática en la Pontificia Universidad Católica de Chile. Licenciado en Sagrada Escritura en el Pontificio Instituto Bíblico de Roma. Entre sus publicaciones cabe mencionar los libros Discipulo de Jesús y Discipulado según la obra de San Lucas (2005) y Discípulo de Jesús y Discipulado. Relatos e imágenes de vocación y misión en la Biblia (2006). 


\section{Propósito}

Estas páginas presentan los criterios que rigen la actual traducción de la Sagrada Escritura llamada Biblia de la Iglesia en América (BIA), cuyos Evangelios ya se han publicado ${ }^{1}$. Estas páginas, pues, buscan responder a una pregunta: ¿Qué hermenéutica está en la base de esta nueva traducción promovida por el Consejo Episcopal Latinoamericano $(C E L A M)$ ?

No es mucho lo que la exhortación apostólica postsinodal Verbum Domini, de Benedicto XVI, trae explícitamente sobre la traducción de la Biblia ( $\left.V D, \mathrm{~ns}^{\circ} 46 ; 115\right)$; estos datos habría que completarlos con lo que la misma exhortación dice sobre la Liturgia y los Leccionarios $\left(\mathrm{ns}^{\circ}{ }^{\mathrm{o}}\right.$ 57; 69).

Para la traducción de la Biblia y su exégesis se requieren competencia forjadas mediante años de estudios y de práctica. Pero una buena traducción no sólo es producto de los principios de la traductología, sino también del arte, pues un buen resultado no se consigue sólo con la puesta en práctica de lo que la ciencia exegética y la traductología postulan. Como traducir es también arte, se requiere una vocación y disposiciones que no se adquieren sólo con la ciencia bíblica o el conocimiento acerca de la teoría de la traducción.

Estas páginas se ocupan de la traducción de la Sagrada Escritura, que no es un libro cualquiera, ni simplemente «un libro de devoción, ni un tratado piadoso, ni un relato edificante, ni siquiera es un compendio de verdades reveladas por Dios a los hombres. La Biblia es la literatura religiosa de un pueblo» (Alonso Schökel \& Zurro, 1977: 18).

Además, desde la perspectiva hermenéutica que estas páginas ofrecen, éstas y otras reflexiones pueden ayudar al conocimiento necesario para determinar la calidad de las Biblias con las que hoy contamos y los criterios que nos permitan saber cuándo emplear una traducción y cuándo otra.

Evangelios de la Biblia de la Iglesia en América (Bogotá 2011), publicación autorizada por las Conferencias Episcopales de Chile y de Colombia. Cfr. Silva Retamales \& Junco Garza, 2011: 197-214. 


\section{La revelación y la función de la Sagrada Escritura}

La revelación es un acto de comunicación de Dios al hombre del todo inesperado y gratuito ${ }^{2}$. Tanto la constitución conciliar Dei Verbum como la exhortación apostólica Verbum Domini presentan la revelación divina en categoría de comunicación, pues Dios, por pura gratuidad, se autocomunica, revelándonos su intimidad y voluntad salvífica en Cristo, su Verbo eterno hecho carne. Esta autocomunicación al hombre que, en cuanto realidad que sucede, es de por sí invitación a participar en la intimidad salvadora de Dios Trino, se nos ofrece hoy por la Tradición y por la Sagrada Escritura. Pero se nos ofrece de tal modo que no se pierde su finalidad original: comunicación y encuentro de Dios con la humanidad, llamado a acontecer hoy (cfr. Lc 19,9) en la persona y obra de Jesús, el Hijo de Dios, por mediación del Espíritu, para una vida en comunión con Dios Trino $\left(V D, \mathrm{n}^{\circ} 6\right)^{3}$.

La Sagrada Escritura, tanto por la revelación que consigna como por ser obra literaria, es un acontecimiento de comunicación que responde a la naturaleza y función de lo que contiene, la revelación de un Dios personal quien sale de sí para buscarnos en amistad. Lo hará en tanto cuanto la Biblia se ofrezca al hombre contemporáneo como mediación óptima de conocimiento de Dios, de encuentro y diálogo con Él.

Así lo dice Verbum Domini: «La palabra que el hombre dirige a Dios se hace también Palabra de Dios, confirmando el carácter dialogal de

2 En un esquema simple y lineal, el acto de comunicación se puede entender como la interacción de un emisor y un receptor, los que comparten un código de signos, permitiendo - por medio de un canal de comunicación (voz, gestos, escritos...)- emitir un contenido o mensaje inteligible, y al otro comprenderlo. Si además de compartir el código de signos y el canal de comunicación, emisor y receptor pertenecen al mismo contexto socio-cultural, la comunicación se hace de comprensión inmediata; a mayor interacción de elementos comunes entre emisor y receptor, mayor comunicación. Cfr. Nida \& Reyburn, 2011: 1338; Silva Retamales, 1997: 223-224.

3 Sobre la revelación como autocomunicación, palabra, encuentro y presencia, cfr. Pié-Ninot, 2006: 242-257. Aún estamos lejos de que la Sagrada Escritura sea mediación de encuentro con el Señor (cfr. Documento de Aparecida, ns ${ }^{\circ}$ 247-249); en una encuesta internacional sobre lectura de la Sagrada Escritura, a la pregunta hecha a quienes se confiesan practicantes acerca de qué modo Ud. ora, sólo el $26 \%$ de los cristianos practicantes argentinos ora leyendo la Sagrada Escritura de un total del 98\% que afirma que, sin embargo, reza con frecuencia; de los filipinos, el 5\% de un total del 99\%; de los españoles, el 12\% de un total del 100\%; de los italianos, el 13\% de un total del $99 \%$; la mayoría de estos practicantes afirma que reza recitando oraciones aprendidas de memoria; a la pregunta, también a los cristianos practicantes, si prefiere leer la Sagrada Escritura o bien literatura religiosa, escuchar una homilía, ver una transmisión de TV de carácter religioso, sólo el 27\% de los argentinos prefieren leer la Biblia, el 33\% de los filipinos, el 14\% de los españoles y el 17\% de los italianos; cfr. Paglia: 2008: 35 y 40).

VERITAS, № 27 (Septiembre 2012) 
toda la revelación cristiana, y toda la existencia del hombre se convierte en un diálogo con Dios que habla y escucha, que llama y mueve nuestra vida»; y más adelante afirma: el Texto Sagrado debe ser considerado «en su naturaleza propia de comunicación que el Señor ofrece a los hombres para la salvación» ( $\left.V D, n^{\circ}{ }^{\circ} 24 ; 45\right)^{4}$. Las Sagradas Escrituras, por tanto, son mediación para este conocimiento, encuentro y diálogo salvífico con Dios.

Ahora bien, el encuentro y diálogo con Dios mediante la Escritura no se consigue por el sólo hecho de leerla. Aunque la Escritura, por la revelación de Dios que consigna, tenga carácter sacramental (cfr. $V D, \mathrm{n}^{\circ}$ 56), no significa que comunica la revelación sin exigir ninguna condición por parte de la misma Escritura como, por ejemplo, traducciones «exactas y adaptadas» (DV, $\mathrm{n}^{\circ}$ 22: ut aptae ac rectae), ni ninguna disposición por parte de quien la lee como, por ejemplo, la fe propia del discípulo de Jesús y la puesta en práctica de lo que lee y cree (Sant 1,2225 ; cfr. $V D$, ns $\left.^{\mathrm{o}} 25-26 ; 50\right)^{5}$.

\section{La Palabra de Dios en el textus bíblico}

Las Sagradas Escrituras en cuanto textos, es decir, tejido de signos literariamente coherentes para aportar significados, son obras de literatura, son biblia (en griego), esto es, una colección de libros escritos en diversas épocas y por diferentes autores con la finalidad de consignar la revelación de Dios a Israel y al Nuevo Israel, la Iglesia.

4 Este es «el modelo teorético-comunicativo-participativo», no sólo propio de Dei Verbum, sino también de Verbum Domini, modelo «que subraya tanto el aspecto de "comunión-comunicación", ya que genera una relación personal $\left(D V, \mathrm{~ns}^{\mathrm{o}} 1 ; 2\right)$, como el aspecto de "participación", ya que a su vez ofrece los "bienes divinos" $\left(D V, \mathrm{n}^{\circ} 6\right)$ como son la verdad, la justicia, el amor, la paz...», Pié-Ninot, 2006: 245. Sobre lenguaje y texto al servicio de la comunicación en una teoría de la traducción, cfr. Egger, 1990: 32-51; Silva Retamales, 1997: 216-227.

5 L. Alonso Schökel (1986: 97) afirma: «La Sagrada Escritura es un libro antiguo que pretende ser actual; encarnado en el tiempo, pretende hablar a todas las generaciones; limitada en lenguaje y horizonte cultural, aspira a ser universal. No podemos destruir esas tensiones, porque únicamente desde su concreción nos habla y busca, en su concreción nos alcanza, solamente en un contacto personal nos mueve. Y no basta apelar a la omnipotencia, omnipresencia y eficacia divinas, porque el camino de Dios es la encarnación». Y J. A. Bengel escribe en su introducción a la traducción del Nuevo Testamento de 1734: «Te totum applica ad textum; rem tota applica ad te. Aplícate todo tú al texto; todo su material aplícatelo a ti», en Martínez, 1984: 560. Cfr. Silva Retamales, 2012: 86-96. 
Esta revelación o palabra divina en lenguaje humano no se encuentra detrás o más allá de letras y textos, sino precisamente en aquello que configura el textus como magnitud literaria coherente y aportadora de significados. Así lo expresa B. Maggioni (1990: 622): «Dios y el hombre no actuaron como dos autores uno junto al otro, sino más bien como uno dentro del otro, cooperando a la producción de un único texto con un solo significado. Por ello, si se quiere comprender lo que quiso Dios comunicar, hay que buscar con atención "lo que los hagiógrafos intentaron significar" $\left(D V, \mathrm{n}^{\circ} 12\right)[\ldots]$. No pasar a través del espesor humano e histórico de la Escritura es olvidar el misterio de la encarnación. La fidelidad a la historia no impide alcanzar la fuerza espiritual y actual de la "palabra", sino que más bien la libera y es su premisa indispensable» ${ }^{6}$.

Entre aquellos emisores (autores bíblicos) y receptores originales (lectores) se comparte, por lo general, un mismo código de signos y un determinado canal de comunicación que contienen los contenidos revelados de la Biblia ${ }^{7}$. Así, de esta forma, la Escritura es «Palabra de Dios que se nos comunica a través de palabras humanas (cfr. 1 Tes 2,13)» (VD, n $\left.{ }^{\circ} 29\right)$. Revelación-Palabra, por un lado, y Letras-Texto, por otro, se pueden «entender en analogía con la presencia real de Cristo bajo las especies del pan y del vino consagrados», ( $\mathrm{n}^{\circ} 56$ ).

Estas Escrituras participan de la condición de Palabra de Dios, porque las notas distintivas de tal las reciben de su analogado principal, el Verbo o la única y definitiva Palabra eterna del Padre, la segunda Persona de la Trinidad hecho hombre por nosotros (Silva Retamales, 2012: 68-79). En la Sagrada Escritura, pues, «se reconoce la Palabra de Dios, que se dirige hoy al mundo, a la Iglesia y a cada uno personalmente» ( $\left.V D, \mathrm{n}^{\circ} 47\right)$.

La condición de inspiradas por Dios (VD, n $\left.{ }^{\circ} 19\right)$ garantiza que la Escritura contenga la automanifestación o revelación de Dios a Israel (Antiguo Testamento) y del Verbo de Dios hecho carne (Nuevo Testamento) como propuesta de encuentro y diálogo con Dios Trino y como oferta de verdad salvífica para todo el que crea y se convierta ${ }^{8}$. Por esto, «aunque el Verbo de Dios precede y trasciende la Sagrada Escritura, en cuanto inspirada por Dios, contiene la palabra divina (cfr. 2 Tim 3,16) en

\footnotetext{
6 Sobre la textualidad del texto y sobre la comprensión de significado, significante y signo y el triángulo semiótico en la lingüística moderna, cfr. Silva Retamales, 1997: 222-223 y nota 3 del presente artículo.

Cfr., al respecto, nota 3 del presente artículo.

Sobre el importante concepto de verdad salvifica (veritatem salutarem) en la constitución conciliar Dei Verbum, cfr. Alonso Schökel, 1969: 405-415; Junco Garza, 2008a: 231-236 y 2008b: 21-24.
} 
modo muy singular» $\left(\mathrm{n}^{\circ} 17\right)$. Es realmente Palabra de Dios viva y eficaz, más cortante que espada de doble filo (Heb 4,12-13).

Sin embargo, queda claro con lo dicho que no hay que identificar sin más la Palabra de Dios con la Escritura, puesto que el Verbo «precede y excede la Biblia»". Por lo mismo, se concluye que «la Palabra de Dios nunca está presente en la simple literalidad del texto» ( $V D, \mathrm{n}^{\circ} 69$ ). Por literalidad del texto se entienden los significados que se atribuyen a tal o cual signo lingüístico sin importar la intención del autor, sin considerar su obra como organización literaria (que incluye género literario) y sin tener en cuenta los contextos socio-culturales y religiosos originales. Se comprende por qué el literalismo fácilmente puede derivar en una lectura fundamentalista de la Biblia, traicionando tanto su sentido literal como espiritual (cfr. $\mathrm{n}^{\circ}$ 44).

La tarea del creyente de cara a la Sagrada Escritura es alcanzar la revelación del Logos (Palabra) consignada en los logoi (palabras) o código de signos que, en cuanto estructura de relaciones literarias coherentes o canal de comunicación, proporcionan los significados que Dios quiere. El lector creyente debe trascender la simple literalidad del texto en la búsqueda creyente del Logos, de modo contrario no alcanzará la revelación de Dios Trino ni su oferta de autocomunicación para vivir en comunión con Él. A la vez, este empeño hermenéutico exige que el traductor no convierta la traducción de la Escritura en «un mero trabajo mecánico» ( $\left.V D, \mathrm{n}^{\circ} 46\right)$, en un trasvasar las letras de un texto en lengua extraña (lengua-fuente: hebreo, arameo, griego) a una lengua que hablen los destinatarios de la traducción (lengua-receptora: castellano). Su función es ofrecer el Logos contenido en los logoi tal como, inspirados, lo fijaron los hagiógrafos en los textos bíblicos.

\section{Algunos desafíos en la traducción de la Sagrada Escritura}

Lo dicho hasta ahora nos permite saber cómo traducir la Sagrada Escritura, pues, precisamente de la identidad y vocación de ésta se deducen los criterios que rigen una buena traducción. Creo que sólo debemos aspirar a conseguir una buena traducción, porque no creo que exista la traducción perfecta ${ }^{10}$.

9 «Mensaje final» de la XII Asamblea General Ordinaria del Sínodo de los Obispos acerca de "La Palabra de Dios en la vida y en la misión de la Iglesia", Octubre 2008, n 3.

10 Cfr. Lapide, 2000. Nida y Taber (1986: 227) afirman que una buena traducción «debe fundarse en tres factores principales: 1) la exactitud con que los receptores entienden el mensaje del original (es decir, su "fidelidad al original", lo cual se refleja en 
Se impone la pregunta: ¿Qué es traducir? Si traducir es preocuparse por la literalidad del texto, ocupándose en cambiar las letras de la Escritura o su código de signos a uno entendible para el lector de hoy (inglés, francés, castellano...), entonces habrá que poner mucho cuidado en que cada palabra de la lengua-fuente sea traducida a un respectivo vocablo de la lengua-receptora, según las posibilidades de ésta. Pero este criterio no satisface en lo más mínimo la identidad y vocación de la Escritura.

Algunos ejemplos. Si seguimos este criterio de traducción, el sustantivo dikaiosýne (92 veces en el Nuevo Testamento) debe traducirse siempre por justicia independiente de sus contextos teológicos y literarios $^{11}$, aunque en Mateo tenga énfasis diversos a los de Pablo y, además, sin mayor preocupación por si los lectores de hoy realmente entienden lo que el autor en aquel tiempo quiso decir (significados objetivos) y conseguir (significados expresivos) con dicho término. Lo mismo ocurre con la traducción de otros muchos vocablos como, por ejemplo, justificar/justificación, gracia, pecado, verdad, vida, santos, padre, casa, matrimonio...

Ahora bien, si traducir es sólo transferir un término o signo lingüístico de la lengua-fuente (hebreo, arameo y griego) a la lengua receptora (castellano), ¿por qué cuando nos encontramos con semitismos y eufemismos traducimos el significado y no el signo? ¿Por qué traducimos por varones donde el hebreo dice literalmente: «No le habría quedado a Nadal... ni uno solo de cuantos orinan contra un muro»? (1 Sm 25,34). ¿Por qué no traducimos: «Está cubriendo sus pies»y, en cambio, preferimos el sintagma hacer sus necesidades o similares, cuando lo que literalmente dice el texto hebreo es lo primero? (Jue 3,24). ¿Por qué en Jeremias traducimos por te han levantado el vestido y te han violado, o similares, cuando el hebreo en su literalidad dice: «Han sido levantadas las colas de tus vestidos y violentados tus talones»? (Jr 13,22). ¿Por qué algunas Biblias traducen: "Allí suscitaré a David un vástago, daré un

la medida en que la gente comprende realmente el sentido); 2) la facilidad de comprensión, y 3) la implicación de experiencias personales como resultado de la propiedad formal de la traducción. Quizás el mejor cumplido que pueda escuchar un traductor de la Biblia es que alguien le diga: "Hasta ahora, no había sabido que Dios hablaba mi lengua"».

11 De inmediato cabe la pregunta: ¿por qué traducir precisamente por justicial justificación/justificar...?, ¿porque así se ha venido traduciendo siempre? Así, Leenhardt, quien afirma: «Somos nosotros quienes cometemos la tontería de traducir esta palabra (dikaiosýne) por "justicia”, o al menos la de no explicar en qué sentido, insólito para nosotros, debe entenderse este último término», en Margot, 1987: 313. 
descendiente a mi ungido», cuando el Salmo 132,17 dice literalmente: "Allí suscitaré a David un vástago, aprestaré una lámpara a mi ungido»? ${ }^{12}$

A su vez, los ejemplos que podemos tomar del Nuevo Testamento son también innumerables: mal de ojo, ojo bueno/malo, odiar/amar a un amo, odiar a los padres, hijo de la diestra, atragantarse la garganta, ensanchar/apretar el corazón, castañetear de dientes...

El criterio de traducir el significado para que la gente que no pertenece a la cultura semita del autor comprenda su contenido o mensaje, ¿no lo podríamos también aplicar a justicia/justificación, verdad, vida, santos, temor del Señor, carne/cuerpo/espíritu...? ¿O es que estos términos son más fáciles de comprender para nuestra gente que aquellos semitismos hebreos y sintagmas griegos? (Margot, 1987: 292-353). Además, si se emplea exclusivamente el criterio de traducir literalmente la letra y la estructura sintáctica de las llamadas lenguas bíblicas, ¿cómo se actualizan para el hombre de hoy los significados expresivos o ilocutivos de la Palabra de Dios? ( $V D, \mathrm{n}^{\circ} 56$; $\mathrm{cfr}$. $\mathrm{n}^{\circ}$ 53). La preocupación por trasvasar a una lengua moderna la literalidad del texto hebreo y griego, ¿será la forma de proceder para que los cristianos de hoy tengan un «fácil acceso» a la Sagrada Escritura $\left(D V, \mathrm{n}^{\circ} 22\right)$ y hagan posible -en este tiempo de nueva evangelización- «una nueva escucha de la Palabra de Dios» $\left(V D, \mathrm{n}^{\circ} 122\right) ?^{13}$

Fuera de lo indicado, se le presenta al traductor el problema de qué texto traduce, pues no cuenta con ningún manuscrito original de la Sagrada Escritura, sino sólo con copias, y éstas, cuando se trata del Nuevo Testamento completo, proceden recién del siglo IV d.C. Por tanto, es altamente probable que aquello que traduce de un modo determinado (con artículo o sin él, en este tiempo verbal o en este otro, con adjetivo o sin él...) y sustentado en el mejor texto uncial del siglo IV, algún otro manuscrito le ofrezca otra posibilidad de traducción y, como ninguno es original, se puede presentar el caso que quien represente mejor el original no sea el Textus Receptus (o texto recibido como original), sino la opción textual de tal o cual manuscrito ${ }^{14}$.

El Textus Receptus del Nuevo Testamento es el Novum Testamentum Graece, Stuttgart 1993, edición 27, de los editores Eberhard y Erwin Nestle, Barbara y Kurt Aland, J. Karavidopoulos, C. M. Martini y B. M. Metzger;

12 Cfr. Biblia de América; Bíblia Sagrada, edição católica, in locus.

13 Sobre el texto de la Sagrada Escritura, los distintos tipos de lectores, los modelos de interpretación y una lectura de la Biblia que no renuncie ni a la fe ni a la razón, cfr. Parmentier, 2007.

14 Cfr. Dias da Silva, 2000: 37-43; Passoni dell'Acqua, 1994: 51ss.; Ortíz, 2003: 3951 , con algunos ejemplos de estudio textual de casos particulares. 
esta misma edición permite conocer, en su amplio aparato crítico, una inmensa gama de diversas opciones textuales.

Como Textus Receptus también se emplea The Greek New Testament, Stuttgart ${ }^{4} 1993$, editado por K. Aland, M. Black, C. M. Martini, B. M. Metzger y A. Wikgren, complementado con $A$ Textual Commentary on The Greek New Testament de B. M. Metzger, Stuttgart 1975. Esta obra tiene el propósito de ofrecer una base científica a las traducciones interconfesionales, por lo que las variantes textuales que trae, las cataloga de la $\{A\}$ a la $\{D\}$ con la finalidad de indicar los diversos grados de certeza de dichas variantes respecto a lo que pudo haber sido el texto original $^{15}$.

En sintesis, dos desafíos mayores se presentan, hasta el momento, en la traducción de la Biblia.

El primer desafío se presenta si sólo se traducen letras y estructuras sintácticas de las lenguas bíblicas: ¿bastaría sólo esto para expresar los significados objetivos y expresivos a los que el lector contemporáneo debe acceder, para conocer la revelación divina que lo interpele y lo abra al don de la comunión con Dios? De nuevo las clarificadoras palabras de Benedicto XVI: para alcanzar el espíritu de la Escritura (esto es, sus significados revelados queridos por Dios), se necesita «trascender la letra [...]. Este trascender no puede hacerse en un solo fragmento literario, sino en relación con la Escritura en su totalidad. En efecto, la Palabra hacia la que estamos llamados a trascender es única» ( $\left.V D, \mathrm{n}^{\circ} 38\right)$.

El segundo desafío en la traducción de la Biblia, la expreso también con una pregunta: ¿Qué textos hebreos y griegos se traducen cuando no existen los originales, sino copias que presentan variadas opciones textuales que —en ocasiones- podrían ser mejor que el Textus Receptus?

\section{Hermenéuticas para una buena traducción de la Sagrada Escritura}

Traducir es recrear, mediante una nueva organización literaria y con análogos niveles de calidad literaria y de impacto expresivo, los

\footnotetext{
15 La $\{\mathrm{A}\}$ corresponde a opción cierta y la $\{\mathrm{D}\}$ a opción dudosa. Las «Normas para la cooperación interconfesional en la traducción de la Biblia» (Roma 1987, pág. 5) pedían que los traductores siguieran The Greek New Testament y, además de los pasajes clasificados en «A Textual Commentary on The Greek New Testament» con $\{A\}$ y $\{B\}$, los traductores «podrán preferir otras variantes que estén bien atestiguadas cuando el pasaje haya sido clasificado con la letra $\mathrm{C}$. Para opciones de diversos manuscritos, aunque antiguo, pero en castellano, contamos con O'Callaghan, 1982.
} 
significados genuinos contenidos en un proceso de comunicación de tiempos pasados como suceso de comunicación llamado a acontecer hoy.

Por tanto, una buena traducción de la Biblia es aquella que comunica a los lectores de hoy el contenido o mensaje revelado expresado por los hagiógrafos y manifestado por Dios, mediante una organización literaria o textus tal, que haga accesible tanto sus genuinos significados como el encuentro autor-lector como acontecimiento actual de comunicación. Como los contenidos o mensajes dependen de sustratos socio-culturales que pocos lectores contemporáneos conocen (por ser propios del siglo I) y se expresan también en un ajeno código de signos y organización literaria, la tarea del traductor es hacer del lector de hoy un auténtico receptor e interlocutor de aquellos contenidos y comunicación de tiempos antiguos. Para esto, el traductor ha de producir, en un código de signos comprensible, una organización literaria o canal de comunicación que le permita al lector alcanzar el estatus de verdadero lector-receptor e interlocutor, esto es, la capacidad de hacerse cargo de modo comprensivo y por sí mismo de los mensaje expresados en los textos bíblicos, disponiéndose a la comunicación con Dios.

Una buena traducción es la que comunica fielmente todos los contenidos de la Sagrada Escritura con la finalidad de ser mediadora de encuentro personal y comunitario con el Señor y, por ello, de discipulado, conversión, comunión y servicio al mundo.

Los contenidos, de los que el traductor tiene que hacerse cargo, son:

a) De los significados objetivos del texto u organización literaria; es decir, hacerse cargo del lenguaje en cuanto medio por el cual un emisor produce enunciados o proposiciones conforme a las normas gramaticales y según un determinado empleo de la lengua; dos elementos hacen tal acto significante: la referencia (de quién o qué cosa se habla o escribe) y la predicación (qué se dice, afirma o niega de alguien o de algo).

b) De los significados expresivos ${ }^{16}$ del texto u organización literaria, como acontecimiento de comunicación; es decir, hacerse cargo del lenguaje en cuanto medio por el cual el emisor busca influir en el receptor con la finalidad de modificar su comprensión, sus intenciones y comportamientos; la fuerza y efectividad de la influencia o del efecto intentado, dependen de muchos factores: de

\footnotetext{
16 Los nombres son diversos, según las escuelas lingüísticas; los significados objetivos también reciben el nombre de denotativos, locutivos o proposicionales; los expresivos también son llamados connotativos, ilocutivos o prolacionales.
} 
la competencia literaria del autor, de la conservación del escrito, de la capacidad que posea el lector para dejarse impresionar, del contexto comunicacional... ${ }^{17}$.

En la Sagrada Escritura sobresalen los significados expresivos de la connotación: el emisor apremia o exige de sus destinatarios la realización de una determinada acción o adquirir una determinada conducta, y la performatividad: Dios, por la fuerza propia de su Palabra, busca provocar la comunión con Él y dar una nueva forma a la existencia del lector creyente; aunque este resultado prolacional no depende exclusivamente de una buena traducción de la Biblia, ésta sí colabora a ello ${ }^{18}$.

El contenido o mensaje son tanto los significados objetivos, es decir, lo que los autores quisieron decir (¿quién habla?, ¿qué dice?) como también -en cuanto realmente intentados por los autores- los significados expresivos, es decir, aquello que los autores quisieron conseguir de sus lectores (2̇ómo lo dice?, ¿qué pretende con ello?) ${ }^{19}$. Sólo abordada desde esta perspectiva, la Palabra de Dios que la Sagrada Escritura contiene se

17 Aristóteles afirmaba «que los medios de persuasión que radican en el razonamiento son de tres clases: "unos radican en el carácter del que habla, otros en situar al oyente en cierto estado de ánimo, otros, en fin, en el mismo discurso, por lo que en realidad significa o por lo que parece significar", Retórica 1355b 10; 1356a 1 (cap. II). De este modo, fijaba la temática de la Retórica: el emisor y sus conocimientos de oratoria deliberativa (persuadir o disuadir), forense (acusar o defender) y epidíctica (honrar o vituperar); el receptor y los múltiples "pliegues" y resonancias del alma humana, y el mensaje y las características de un buen tema interpelador (captatio benevolentiae)», Silva Retamales, 1997, nota 34.

18 Para la importancia de intentar, en una traducción, reflejar los significados expresivos, compárense las siguientes dos traducciones de 2 Corintios 7,2-4: «Dadnos cabida en vuestro corazón: a nadie hicimos agravio; a nadie ocasionamos ruina, a nadie sonsacamos nada. No digo esto para condenación; que ya antes tengo dicho que estáis en nuestros corazones para juntos morir y juntos vivir. Mucha es la confianza que uso con vosotros; henchido estoy de consolación, estoy que reboso de gozo en medio de toda esta tribulación nuestra» (Nuevo Testamento Trilingüe, edición crítica de J. M. Bover y J. O’Callaghan, in locus). Y la traducción (aún no definitiva) de la BLA: «iHágannos un lugar en su corazón! Pues a nadie perjudicamos, a ninguno arruinamos, a nadie explotamos. No digo esto para condenar a alguno, porque ya les he dicho que los llevamos en nuestros corazones, tanto en la vida como en la muerte. Les tengo mucha confianza y grande es mi orgullo por ustedes, lo que me llena de consuelo y me hace desbordar de alegría a pesar de todas nuestras tribulaciones». Sobre la performatividad de la Palabra de Dios, cfr. Silva Retamales, 2012: 96-101.

19 Varias son las funciones prolacionales del lenguaje como, por ejemplo, funciones asertivas, directivas, expresivas, declarativas..., tipos y clasificación que dependerá de la escuela lingüística de la que se trate. 
transformará en «camino de salvación por medio de la fe en Jesucristo» (2 $\operatorname{Tim} 3,15)$.

El traductor de la Biblia no puede tratar el lenguaje bíblico «sólo como fuente de información (función locutiva o proposicional)», sino que debe rescatar todas las funciones empeñadas en cada parte de la Sagrada Escritura (Silva Retamales, 1997: 221) ${ }^{20}$.

Para traducir el contenido completo de un texto bíblico es imprescindible emplear hermenéuticas que trasciendan la literalidad del texto bíblico, haciendo de la traducción una obra puesta al servicio del encuentro y la comunicación del lector creyente con el Revelador y su revelación ${ }^{21}$. Si traducir es «presentar la oferta de sentido contenida en un proceso de comunicación de tiempos pasados, como oferta de sentido para los hombres de nuestro tiempo» (Egger, 1990: 253), entonces hay, por lo menos, tres aproximaciones hermenéuticas imprescindibles para una buena traducción de la Sagrada Escritura: la hermenéntica académica, la teológica y la eclesio-pastoral.

La hermenéutica académica tiene que hacerse cargo del tenor literal de las Escrituras, no de la «simple literalidad del texto», en expresión de Benedicto XVI, en cuanto magnitud literaria coherente preñada de significados en orden a la comunicación. Es decir, hacerse cargo del código de signos (lenguas), del canal de comunicación (textus) y de los contextos de autores y lectores originales, pues Dios habló «en la Sagrada Escritura por hombres y a la manera humana» (DV, $\mathrm{n}^{\circ} 12$; cfr. $V D, \mathrm{n}^{\circ}$ 29). El hecho de ocuparse de aquello que realmente pretendieron expresar los autores de la Biblia lo exige el misterio de la encarnación, pues así como el Verbo se hizo carne, el misterio de Dios se hizo logoitextus, esto es, organización literaria con los condicionamientos y debilidades propias de su época.

El sentido literal es el principal sentido que hay que descubrir y que traducir; todos los otros encuentran su fundamento en éste $\left(V D, \mathrm{n}^{\circ}\right.$ $37)^{22}$. Sin embargo, la tarea del traductor no termina cuando comprende

\footnotetext{
20 Pertenece a la historia de la exégesis «el dato de que la Biblia se interpretó por mucho tiempo en función de los dogmas teológicos, favoreciendo sólo la dimensión informativa de la comunicación humana. Cuando la teología entró a la Universidad y la Lectio Divina, que se venía practicando desde el tiempo de los monjes, se cambió por la Lectio Scholastica, centrada en la búsqueda de una auctoritas con el fin de justificar la reflexión teológica, la interpretación bíblica se hizo en función de la veracidad de los enunciados dogmáticos. La Escritura se empleaba como sedes argumentorum o depósito de dicta probantian, Silva Retamales, 1997: 218.

21 El capítulo 2 de Nida \& Reyburn (2011: 39-60), lleva por título: «Traducir es comunicar». Cfr. Egger, 1990: 74-77.

22 Sobre el sentido literal, véase más adelante.
} 
lo que autor humano quiso comunicar en su tiempo a sus lectores, «ni cuando logramos presentar el origen y la evolución de un texto, sino cuando captamos lo que el Señor nos quiere comunicar, cuando logramos la lectura de la Escritura guiada por el Espíritu, cuando actualizamos la Palabra de Dios» (Junco Garza, 2008c: 35). De aquí la importancia de la siguiente hermenéutica, complemento indispensable de la hermenéutica académica.

La hermenéntica teológica busca descubrir lo que Dios quiso manifestar por los hagiógrafos o autores inspirados. Porque Dios es verdadero autor de la Escritura, la globalidad y unidad de su contenido es fuente de significados revelados y oferta de comunión. Por tanto, para acceder a la verdad completa (cfr. Jn 16,13) y al sentido exacto y salvífico de todo lo revelado, se requiere atender la organicidad de toda la Escritura, recurriendo para ello a la analogía de la fe (cfr. Rm 12,6) y a la tradición viva de la Iglesia $\left(D V, \mathrm{n}^{\mathrm{o}} 12 ; V D, \mathrm{n}^{\mathrm{o}} 34\right)^{23}$.

Pero, ¿desde dónde y para qué se interpreta y traduce la Sagrada Escritura? Se requiere un tercer momento que permita sintetizar y autentificar los resultados y, a la vez, ofrecerlos conforme a la vocación y misión de Iglesia y de la revelación encargada a ella. Hablamos de la hermenéutica eclesio-pastoral.

La bermenéutica eclesio-pastoral se ocupa de la síntesis de las dos hermenéuticas anteriores y de la autenticidad de sus resultados con la finalidad de que se cumpla el propósito de la revelación que la Sagrada Escritura consigna. Esto significa que hay que interpretar y traducir la Biblia para el hombre y la mujer de hoy de modo que efectivamente conviertan a la persona y la comprometan en el seguimiento de Jesús y en el servicio al mundo ${ }^{24}$. Este diálogo entre Dios y su revelación con la vida y la historia del lector, posible gracias a buenas traducciones, valida la interpretación de la Escritura desde la vida y la historia de personas y comunidades, aproximación hermenéutica que —-purificándola de sus excesos - ha dado muchos frutos de santidad y testimonio discipular en Latinoamérica. Gracias a la hermenéutica eclesio-pastoral se puede hacer

\footnotetext{
23 Sobre estas normas teológica en Dei Verbum, no 12, cfr. Junco Garza, 2008c: 3542.

24 Egger (1990: 81): «La calidad de una traducción se mide no sólo por su fidelidad a los autores y al texto, sino también por su orientación a los lectores». Según Paglia, (2008: 19-20), una de las conclusiones de la encuesta es que la Biblia, por parte de los que se confiesan practicantes, es amada porque contiene la Palabra de Dios, sin embargo es para ellos difícil de entender ( «L'inchiesta fa emergere inoltre una notevole ignoranza circa le Scritture»; así, más del 60\% de los encuestados, catalogados como practicantes); de aquí, lo indispensable de buenas traducciones y del acompañamiento adecuado para la lectura comprensiva de la Biblia, entre otras soluciones.
} 
realidad aquella inmensa capacidad que tiene la Palabra de Dios de «dialogar con los problemas que el hombre ha de afrontar en la vida cotidiana», de responder a sus interrogantes, de ensanchar sus valores, de satisfacer sus propias aspiraciones $\left(V D, \mathrm{n}^{\circ} 23\right)$.

\section{Fidelidades para una buena traducción de las Escrituras}

Una traducción «exacta y adaptada» de la Biblia, al igual que su interpretación, requiere - por lo menos- dar respuestas a tres tipos de preguntas y cuidar tres fidelidades, respuestas y fidelidades que se condicionan y complementan mutuamente.

Los tres tipos de preguntas:

a) Si Dios habla en la Escritura por medio de hombres y en lenguaje humano ( $\left.D V, \mathrm{n}^{\circ} 12\right)$, hay que preguntarse: ¿Qué dice el texto? o ¿cuál es el sentido literal que comunicaron los hagiógrafos a sus lectores segun sus circunstancias socio-culturales y religiosas?

b) Si los autores, inspirados por Dios, son verdaderos productores de significados y Dios, en cuanto autor de toda la Escritura, hace de ésta una historia de salvación que escapa a la contemporaneidad de cada hagiógrafo, hay que preguntarse: ¿Qué quiso manifestar Dios mediante esos hagiógrafos y textos bíblicos? Esta pregunta amplía el horizonte de la anterior, indicándonos que la revelación no se agota en lo que expresaron los autores humanos, sino también hay que hacerse cargo de lo que Dios quiso manifestar mediante ellos, pues solo Dios, verdadero autor de la Biblia, tiene el horizonte completo de la historia de la salvación ${ }^{25}$. Las respuestas a la pregunta anterior y a ésta, en íntima complementación, permiten aprehender los significados del texto bíblico en la unidad de la revelación e historia de la salvación conducida por Dios, y

c) Si, por un lado, el lector contemporáneo no conoce el código de signos empleado por autores y lectores del tiempo bíblico ni el ambiente socio-cultural y religioso del que ellos se nutren y, si por otro lado, la Biblia es una mediación fundamental para el

\footnotetext{
25 Sin definirlo ni expresarlo explícitamente, la constitución conciliar Dei Verbum, cuando habla de cómo interpretar la Escritura ( $\left.D V, \mathrm{n}^{\circ} 12\right)$, apunta al llamado sentido pleno. Cfr. VD, ns ${ }^{\circ}$ 36-37; Pontificia Comisión Bíblica, La interpretación de la Biblia en la Iglesia (Abril 1993), II B 3.
} 
seguimiento del Señor y la vida de fe, hay que preguntarse: ¿Cómo traducir para el lector contemporáneo en una organización literaria coherente y actual, análoga a la original, el contenido revelado con aquel impacto en los lectores originales que los impulsaba a seguir a Jesús, dando testimonio alegre de él, incluso hasta dar la vida?

La traducción, como ejercicio literario que busca hacer posible la comunicación, no tiene sentido cuando autores y lectores comparten un idéntico código de signos, un igual canal de comunicación y un mismo contexto vital e histórico, porque ambos (autor y lectores) se entienden sin necesidad de mediador. Por lo mismo, estos lectores no necesitan información alguna por parte del emisor o autor bíblico.

Sin embargo, los lectores de hoy, de sociedades occidentales e industrializadas, no compartimos con los autores bíblicos ni el contenido, ni el código de signos, ni el contexto vital e histórico. En este caso, la traducción debe ser un ejercicio literario que haga realmente posible la comunicación entre los autores de los tiempos bíblicos y los lectores del siglo XXI. Tarea del traductor es convertir a los lectores de hoy, por la calidad y pertinencia de la mediación literaria, en auténticos receptores e interlocutores del emisor bíblico. Por tanto, «no sólo es importante la pregunta acerca del contenido y la forma lingüística del original, sino también la pregunta acerca de quién va a ser el receptor de la traducción» (Egger, 1990: 77).

La puesta en práctica honesta de las respuestas a estas preguntas por parte de traductores e intérpretes de la Biblia ${ }^{26}$ exige las tres siguientes fidelidades:

a) Después de reconstituir lo mejor posible el texto bíblico gracias a la crítica textual, se pide al traductor fidelidad a los autores bíblicos y a los sentidos literales que expresaron. El «sentido literal» son los significados objetivos y expresivos, intentados por los autores bíblicos, según se deducen de la obra como «organización literaria» (en la que se incluye el género literario), leída en los contextos socio-culturales y religiosos de autores y lectores originales ${ }^{27}$.

26 Traducir «forma parte de la tarea interpretativa», VD n ${ }^{\circ} 46$.

27 La Pontificia Comisión Bíblica afirma en La interpretación de la Biblia en la Iglesia, Abril 1993, II B 1, que no es solamente legítimo, «sino indispensable, procurar definir el sentido preciso de los textos tal y como han sido producidos por sus autores, sentido llamado "literal"... El sentido literal no se debe confundir con el sentido "literalista" al cual se adhieren los fundamentalistas. No basta traducir un texto palabra por palabra 
Para comprender el sentido literal hay que penetrar en el secreto del lenguaje, de su uso y de su organización literaria, conforme al tiempo de autores e interlocutores; de aquí la importancia de aquellas ciencias humanas y de sus métodos de investigación que nos abren el camino hacia el lenguaje y sus significados (cfr. VD, $\mathrm{n}^{\mathrm{o}} 32$ ).

b) Fidelidad a lo que Dios quiere revelarnos por medio de los hagiógrafos, es decir, fidelidad a lo que Él quiso manifestar en las palabras de ellos y en su determinada organización literaria. Este es el sentido llamado espiritual, que permite alcanzar la realidad de fe que los textos bíblicos expresan y que sólo es posible conocerlo en unidad y articulación íntima con los sentidos literales. La Pontificia Comisión Bíblica define el sentido espiritual como «el sentido expresado por los textos bíblicos, cuando se los lee bajo la influencia del Espíritu Santo en el contexto del misterio pascual de Cristo y de la vida nueva que proviene de Él» $»^{28}$.

A los sentidos espirituales, queridos por Dios, se accede mediante la lectura creyente de la historia de Dios con los hombres, en cuanto suceso de diálogo salvífico llamado a acaecer hoy. La correcta interpretación de la Sagrada Escritura sólo se alcanza cuando se aclara «el significado del texto bíblico como Palabra actual de Dios» ${ }^{29}\left(V D, \mathrm{n}^{\circ} 33\right)$. Si sólo existe la fidelidad al lenguaje literario de los autores humanos, la Escritura se convierte en un texto del pasado que nada tiene que aportar a la vida y al caminar de la Iglesia y del hombre de hoy.

Los sentidos espirituales sólo se comprehenden en la Iglesia, es decir, por la fe eclesial. La razón es porque, en la naturaleza misma de la Biblia, está el hecho de haber sido escrita «por el Pueblo de Dios y para el Pueblo de Dios, bajo la inspiración del Espíritu Santo», (VD, $\left.\mathrm{n}^{\circ} 30\right)$. Esto significa que sólo «la fe eclesial» ( $\left.\mathrm{n}^{\circ} 29\right)$ y un «profundo espíritu eclesial» ( $\mathrm{n}^{\circ} 47$ ) hacen posible la necesaria «eclesialidad» para comprehender sentidos literales y espirituales de la Biblia ( $\mathrm{n}^{\circ}$ 30). Porque la Biblia es el libro de la Iglesia, «el lugar originario de la interpretación escriturística es la vida de la Iglesia» y, a su vez, la lectura de la Escritura en la fe eclesial, aumenta la misma vida eclesial ( $D V, \mathrm{~ns}^{\circ}$ 29-30). Desde esta perspectiva, más que un destinatario, el lector creyente, se transforma, por su inserción en la

para obtener su sentido literal. Es necesario comprenderlo según las convenciones literarias de su tiempo».

28 La interpretación de la Biblia en la Iglesia, II B 2, citado en VD, $\mathrm{n}^{\circ} 37$.

29 La interpretación de la Biblia en la Iglesia, III C 1, citado en VD, $\mathrm{n}^{\circ} 33$. 
vida eclesial animada por el Espíritu Santo, en un interlocutor a quien Dios busca con ansia para dialogar con él y ofrecerle lo mejor de sí, su Hijo hecho hombre en cuanto Palabra de vida y verdad.

Una importante consecuencia es que desde la vida y para la vida, el lector y la comunidad creyente pueden interpretar y actualizar auténticamente la Palabra de $\operatorname{Dios}^{30}$; y, finalmente,

c) Fidelidad a la Iglesia y a su misión, la que existe para evangelizar, es decir, para anunciar al Revelador del Padre como camino, verdad y vida. Esto significa que, si fue ésta precisamente la revelación que Dios le confió a la Iglesia y, con ello, la Sagrada Escritura, la fidelidad a la Iglesia y su misión exige necesariamente la fidelidad al lector de la Sagrada Escritura, al Pueblo de Dios que no puede ser evangelizado si no comprende lo que lee. La fidelidad a la labor evangelizadora de la Iglesia, por tanto, se vuelve fidelidad a la evangelización de los lectores mediante la Sagrada Escritura, evangelización que no se da por el hecho de tener una Biblia, sino por hacer del lector un receptor e interlocutor, por mediación de la Escritura, del encuentro personal con el Señor resucitado. Pero para esto, hay que procurar comunicar al lector contemporáneo, en su actual código de signos y con la máxima calidad y claridad que el canal de comunicación permita, lo que los hagiógrafos dicen y lo que Dios revela por ellos.

$\mathrm{Al}$ respecto, el testimonio del etíope, ministro de la reina Candace, resulta decidor: «¿Entiendes lo que estás leyendo? -pregunta Felipe-... ¿Cómo lo voy a entender si nadie me lo explica? — responde el etíope-... Te ruego que me digas a quién el profeta se refiere, ¿a sí mismo o a otro?... Y Felipe le anunció la buena noticia de Jesús» (Hch 8,30-31.34).

\section{Traducir, para encontrar la Palabra de Dios en las Escrituras}

Teniendo claro que una cosa es traducir y otra muy distinta sustituir, acomodar, transcribir, parafrasear..., nos hacemos la pregunta: ¿Cómo traducir un libro bíblico para que el lector, trascendiendo los logoi, alcance el Logos revelado (Jesucristo) como mediación de conocimiento del Padre y fuente de comunión con Él? Es decir, ¿cómo traducir un libro bíblico

\footnotetext{
30 Cfr. Junco Garza, 2008a: 354-359; Huning, 2007, con amplia bibliografía; Lugo, 2008: 65-80.
} 
para que el lector de hoy encuentre la Palabra de Dios en las Escrituras? (cfr. $D V, \mathrm{n}^{\circ} 72$ ).

Si la traducción es un ejercicio literario mediante el cual el traductor replica literalmente en la lengua-receptora (el castellano) las unidades lingüísticas de la lengua-fuente (el hebreo y griego), esta traducción recibe el nombre de equivalencia formal. El interés se pone en la letra del texto, descuidándose lo que pedía la constitución conciliar Dei Verbum de poner atención «a las formas nativas usadas de pensar, de hablar o de narrar vigentes en los tiempos del hagiógrafo» tal como en aquella época solían usarse en el trato corriente entre los hombres (DV, $\left.\mathrm{n}^{\circ} 12\right)$. Además, por parte del traductor de equivalencia formal, no existe mayor preocupación o se piensa que no es relevante que el lector entienda o no la traducción, pues no se asume que «el paso de una lengua a otra comporta necesariamente un cambio de contexto cultural: los conceptos no son idénticos y el alcance de los símbolos es diferente, ya que ellos ponen en relación con otras tradiciones de pensamiento y otras maneras de vivir» ${ }^{31}$.

El traductor que sólo tenga en cuenta la literalidad de la Escritura y no ponga atención a todo su contenido (significados objetivos y expresivos) ni se preocupe por expresar dicho contenido en una organización literaria al alcance socio-cultural del lector de hoy, puede fácilmente transformar su empeño en una traducción literalista o de equivalencia formal con el peligro de fomentar lecturas fundamentalistas de la Escritura (cfr. $\left.V D, \mathrm{n}^{\mathrm{O}} 44\right)^{32}$.

El lector de hoy, entonces, queda lejos de alcanzar la condición de receptor e interlocutor, condición a la que está llamado para entrar en diálogo y comunión con Dios.

Ahora bien, si la traducción se entiende como un ejercicio literario de mediación para que la lectura creyente de la Escritura (traducida) acontezca como encuentro y comunicación con la Palabra de Dios, ¿se puede conseguir esto con la sola conversión al castellano (lenguareceptora) de los datos literarios de las lenguas-fuentes?

31 «Las cosas dichas en hebreo no tienen la misma fuerza cuando se traducen a otra lengua; cosa que ocurre no sólo con este libro, sino también con la misma ley, los profetas y los otros libros, los cuales ofrecen no pequeñas diferencias cuando se leen en su lengua original», del Prólogo del Eclesiástico. Cfr. Pontificia Comisión Bíblica, La interpretación de la Biblia en la Iglesia, IV B, citado en VD, n 115.

32 Algunas de las Biblias que siguen el criterio de la equivalencia formal son: NacarColunga, Cantera-Iglesias, Biblia de Jerusalén; el Nuevo Testamento de Bover-O'Callaghan. Sobre la labor del traductor y los riesgos más importante al traducir, cfr. Silva Retamales \& Junco Garza, 2011: 208-212; también Nida \& Reyburn, 2011: 103-121. 
Si realmente se busca que el misterio de Dios se entienda y se experimente en la propia vida, el traductor debe emplear el código de signos propio del lector contemporáneo, código que no es sólo una lengua, sino un lenguaje y un uso concreto, de forma que acceda con facilidad al conocimiento de un Dios personal y, convertido en receptor e interlocutor, experimente el diálogo salvífico con Él. Este tipo de traducción pone el énfasis en traducir el espiritu de las Escrituras en favor del lector (cfr. 2 Cor 3,6), y recibe el nombre de traducción de equivalencia dinámica.

Mientras la traducción de equivalencia formal está orientada a reproducir la estructura del texto original o lenguaje de salida (fonética, léxica, sintáctica), la de equivalencia dinámica está orientada a dar a conocer los significados del texto y a replicar los efectos en el lector, considerando las posibilidades de comprensión de los lectores a los que se dirige (lenguaje de llegada).

La traducción de equivalencia dinámica parte de la base que los niveles de comprensión y comunicación entre emisores originales y lectores de hoy son del todo desiguales. Mientras en la comunicación por textos escritos en el siglo I, los emisores tienen verdaderos auditores, correspondientes a nuestros lectores-receptores ${ }^{33}$, que los entienden sin grandes dificultades, pues comparten significados y contextos, en la comunicación actual mediante esos mismos textos bíblicos, aquellos emisores sólo tienen lectores, no receptores ni menos interlocutores, en el sentido de que poco entienden los significados objetivos y expresivos manifestados por aquellos emisores. Tarea del traductor es, mediante una buena traducción, acortar lo más posible esta brecha.

Hay otros tipos de traducciones como la de tipo mixta o concordante (entre equivalencia formal y dinámica) o la de lenguaje llano o popular ${ }^{34}$.

Sólo gracias a las buenas traducciones de la Biblia y, por lo mismo, a su correcta interpretación, va a florecer «una nueva etapa de mayor amor a la Sagrada Escritura por parte de todos los miembros del Pueblo de

\footnotetext{
33 Los textos en la antigüedad se componían, más que para ser leídos, para ser recitados o leídos por uno a diversos grupos (lectura colectiva) y se concebían sólo como un apoyo para la comunicación oral, forma primaria de comunicación. Por tanto, se escribían para ser escuchados (cfr. Jn 12,34), pues, entre otras razones, un gran número de gente no sabía leer ni escribir (se calcula que el $90 \%$ de la población del siglo I era analfabeta). Cfr. Guijarro: 2010: 106-110 y 147-149; en pág. 149: «Los textos escritos, lo mismo que los orales, estaban destinados a la representación oral, que con frecuencia exigía la actualización y la interpretación».

34 Algunos teóricos de la traducción distinguen tres tipos de traducciones: la fiel a la estructura (equivalencia formal), a los significados (traducción mixta o concordante) y al efecto en el lector (equivalencia dinámica). Como se ve, la denominación va a depender del autor del que se trate.
} 
Dios, de manera que, mediante su lectura orante y fiel a lo largo del tiempo, se profundice la relación con la persona misma de Jesús» ${ }^{35}$.

\section{Ejemplos de traducción de los Evangelios de la BIA}

Termino con algunos ejemplos tomados de los Evangelios de la Biblia de la Iglesia en América $(B I A)^{36}$, para mostrar diversas dimensiones de una traducción de la Sagrada Escritura que tiene la pretensión de poner en práctica los criterios aquí propuestos.

A) «Dichosos los que tienen hambre y sed de vivir según el plan de Dios...»: Mt 5,6

\begin{tabular}{|c|c|c|}
\hline $\begin{array}{c}\text { Texto Griego } \\
\text { Textus Receptus: } \\
\text { Novum Testamentum } \\
\text { graece } 271993 .\end{array}$ & $\begin{array}{c}\text { Traducción literalista } \\
\text { El traductor trasvasa } \\
\text { letras y relaciones } \\
\text { sintácticas de la lengua- } \\
\text { fuente a la lengua- } \\
\text { receptora. }\end{array}$ & \begin{tabular}{|c|} 
Evangelios de la BIA \\
El traductor, como mediador, \\
traslada significados y \\
posibilita un acontecimiento \\
de encuentro y \\
comunicación.
\end{tabular} \\
\hline 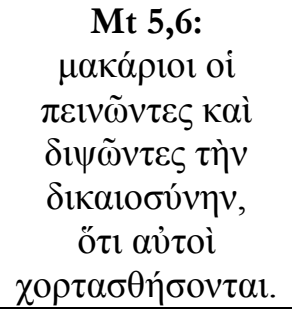 & $\begin{array}{c}\text { BOVER - } \\
\text { O'CALLAGHAN: } \\
\text { Bienaventurados los que } \\
\text { tienen hambre y sed de } \\
\text { justicia, porque ellos } \\
\text { serán saciados. }\end{array}$ & $\begin{array}{c}\text { BIA: } \\
\text { Dichosos los que tienen } \\
\text { hambre y sed de vivir según } \\
\text { el plan de Dios, porque él } \\
\text { los saciará. }\end{array}$ \\
\hline
\end{tabular}

\section{Comentario:}

—¿Cuál es el significado de justicia (dikaiosýne) en Mateo? Evidentemente no se refiere a la justicia social distributiva (que es lo que entiende la mayoría de los lectores del siglo XXI), sino a aquella vida divina regalada al hombre en virtud del misterio pascual del Señor, por tanto, independiente de todo mérito, que hace realidad una existencia humana y comunitaria conforme al plan salvador de Dios. Lo justo son las acciones humanas que, porque el creyente participa de la vida de Dios que redime, realizan su voluntad. De aquí la traducción de vivir según el plan de Dios (o algún otro sintagma que exprese lo dicho). Algo similar ocurre con el término justificación

35 Propositio $\mathrm{n}^{\circ} 9$ de la XII Asamblea General Ordinaria del Sínodo de los Obispos del Sínodo de la Palabra, Octubre 2008, citado en $V D, \mathrm{n}^{\circ} 72$.

36 Véase nota 1 del presente artículo. 
en Pablo, de la misma raíz en griego que justicia (como en castellano); si el griego dikaiosis se traduce por justificación, ¿qué entendería el lector de hoy?, ¿por qué en vez de traducir la palabra no intentamos traducir el significado que el Apóstol le da al signo en un código y canal de comunicación propios del lector contemporáneo, haciéndolo lector-interlocutor? ? $^{37}$

- ¿Por qué poner el pronombre él, al final del versículo, si éste no está en el texto griego? Es claro que con «serán saciados» estamos ante un pasivo divino o teológico, donde el sujeto del verbo es Dios, lo que perfectamente sabe un lector creyente del siglo I («porque Dios los saciará»); por tanto, lo único que aquí se permite el traductor es explicitar el sujeto en beneficio de la comprensión del lector ${ }^{38}$. De este modo, hace un esfuerzo por convertir al lector de hoy en auténtico receptor e interlocutor de un mensaje que, aunque antiguo, es también para él.

\section{Conclusión}

Así como este ejemplo, se pueden dar muchos otros, tanto de palabras que tienen un significado diverso en el siglo I como de la necesidad de hacer explícito lo que está implícito en el texto bíblico en razón de que los lectores de hoy no comparten con los autores o emisores de ayer (los del tiempo bíblico) el código de signos ni el sustrato vital e histórico.

\footnotetext{
37 Varias son las Biblias que, conscientes de la dificultad de comprensión de los términos justicia/justificar/justificación/justo para el lector contemporáneo, buscan traducir su significado, con mejor o peor resultado, cfr. O'Callaghan, 1982: 148-149. Dada la dificultad de traducir dikaiosýne y términos de la misma raíz, la única solución para muchos, consiste en traducir literalmente por justicia, justo, justificar... y, luego, poner notas para explicar su sentido; sin embargo, «ésta es una solución cómoda que en todo caso no ayuda a los oyentes de una lectura pública de los textos en cuestión, puesto que en tales ocasiones no se lee la nota explicativa», Margot, 1987: 306, esp. 300-314). Ver estudio y posibilidades de traducción de justicia/justificación en Schrenk, 1966: II, 12531289 y 1324-1326; Castaño Fonseca, 1997.

38 Sobre el pasivo divino y su empleo en el Nuevo Testamento, cfr. Zerwick, 1997: n² 236; Martínez, 1984: 372-373.
} 
B) «Somos servidores a los que nada hay que agradecer...»: Lc 17,10

\begin{tabular}{|c|c|c|}
\hline 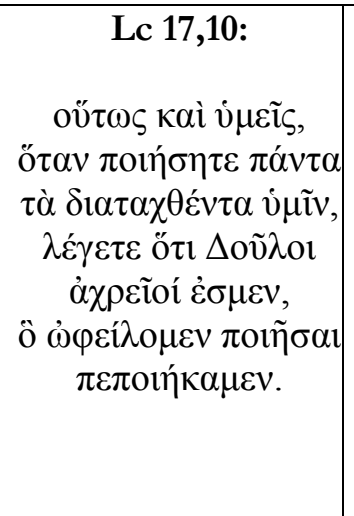 & $\begin{array}{c}\text { BOVER - } \\
\text { O'CALLAGHAN: } \\
\text { Así también vosotros, } \\
\text { cuando hubiereis hecho } \\
\text { todo lo que se os } \\
\text { ordenó, decid: Siervos } \\
\text { somos sin provecho } \\
\text { [otras traducciones: } \\
\text { «Somos unos siervos } \\
\text { inútiles...»]; lo que } \\
\text { debíamos hacer, eso } \\
\text { hemos hecho. }\end{array}$ & $\begin{array}{l}\text { También ustedes, cuando } \\
\text { hayan hecho todo lo que } \\
\text { Dios les manda, digan: } \\
\text { Somos servidores a los que } \\
\text { nada hay que agradecer, } \\
\text { porque no hicimos más que } \\
\text { cumplir con nuestra } \\
\text { obligación. }\end{array}$ \\
\hline
\end{tabular}

\section{Comentario:}

—¿Qué entenderá el lector de hoy cuando lee: «Somos unos siervos inútiles; no hemos hecho más que lo que teníamos que hacer»? (traducción de equivalencia formal). ¡Este siervo, con los tiempos que corren, no tiene nada de inútil! El adjetivo ajreios se dice tanto de algo o alguien inútil, sin provecho, como de alguien que no tiene cualidades que merezcan ser alabadas ni agradecidas (García, 2011, in locus); fundados en este último significado se propone la traducción de la $B I A$, procurando así que su sentido sea del todo claro para el lector contemporáneo.

-De nuevo aparece lo del pasivo divino en «lo que se os ordenó» (sujeto implícito: Dios), que en la $B I A$ se explicita: «Dios les manda...».

\section{Conclusión:}

Se trata ahora de buscar la riqueza de significados de los términos en sus contextos e intentar traducciones que, fundadas en el sentido literal, sean comprensibles para el lector de hoy. Así ya lo hicieron El Libro del Pueblo de Dios, la TOB, La Biblia, traducción en lenguaje actual..., respecto a este pasaje. Sin embargo, para esto hay que vencer aquello de que siempre se ha traducido asi («Siervos inútiles somos...»), entrando en el inconsciente bíblico colectivo. 
C) «iAsi que dicen que tiene que venir primero Elías a restablecerlo todo?»: $\mathrm{Mc}$ $9,11-13$

\begin{tabular}{|c|c|c|}
\hline 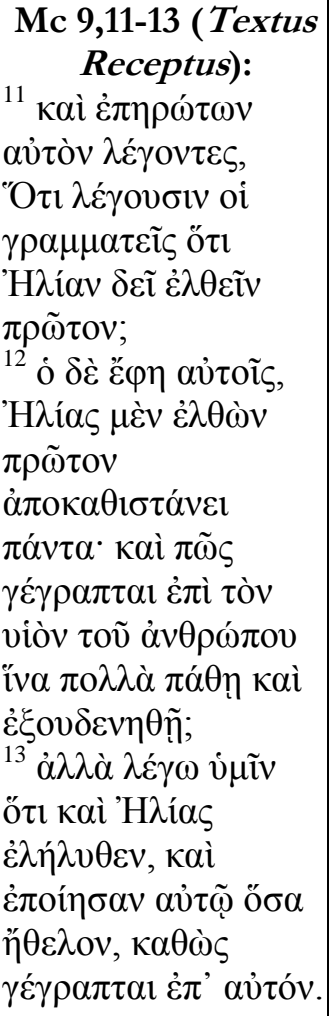 & $\begin{array}{l}12 \text { El les dijo: Elías } \\
\text { ciertamente, viniendo } \\
\text { primero, restaurará todas } \\
\text { las cosas; ¿y cómo está } \\
\text { escrito del Hijo del } \\
\text { hombre que ha de } \\
\text { padecer muchas cosas y } \\
\text { ser menospreciado? } \\
13 \text { Pues bien, os digo que } \\
\text { sí ha venido Elías y que } \\
\text { hicieron con él cuanto } \\
\text { quisieron, según está } \\
\text { escrito de él. }\end{array}$ & $\begin{array}{l}12 \text { Él les contesto: ¿Así que } \\
\text { dicen que tiene que venir } \\
\text { primero Elías a restablecerlo } \\
\text { todo? Entonces, ¿por qué } \\
\text { afirman las Escrituras que el } \\
\text { Hijo del hombre sufrirá } \\
\text { mucho y será despreciado? } \\
{ }^{13} \text { Les aseguro que de todas } \\
\text { formas Elías ya vino e } \\
\text { hicieron con él lo que } \\
\text { quisieron, tal como afirman } \\
\text { las Escrituras acerca de él. }\end{array}$ \\
\hline
\end{tabular}

\section{Comentario:}

- La traducción de la $B I A$ tiene en cuenta tres razones.

La primera es la dificultad de entender una versión como la de Bover - O'Callaghan, Biblia de Jerusalén y otras, pues si Elías viene antes de Jesús a restaurarlo todo (lenguaje de redención) ${ }^{39}$, ¿a qué viene el Hijo del hombre cuando sabemos que restablecer es precisamente su obra?; ¿cómo entender entonces la afirmación de la Escritura? (Mc 9,12-13); ¿quién es en realidad el que redime o restablece todo?, ¿Elías o el Hijo del hombre y su misterio pascual?

39 El verbo griego apokathistáo (de apokathistemi) significa poner todo en su estado primitivo, donde estaba o como estaba antes; traer de vuelta; restaurar; restablecer; restituir; se emplea en Mal 3,24 LXX. El mismo verbo lo encontramos en Mt 12,13; Mc 8,25, y sobre todo en Hch 1,6. 
La segunda razón es entender como pregunta, con muchos comentaristas, no sólo la segunda parte de 9,12, sino también la primera, lo que resuelve las dificultades de comprensión del texto ${ }^{40}$. Según la traducción de la $B I A$, los maestros de la Ley afirman que, según las Escrituras, Elías tenía que venir primero a restaurarlo todo; Jesús les recuerda a sus discípulos esta afirmación común en su tiempo $^{41} \mathrm{y}$, con referencias implícitas a las Escrituras (Is 53,3; Sal 22,7; 1 Re 19,2.10), pone las cosas en su lugar respecto a la función de Elías: quien tiene que venir a restaurarlo todo no es el profeta Elías, sino el Mesías, y lo hará mediante el sufrimiento, tal como lo prometió Dios en las Escrituras del Antiguo Testamento. Además, acerca de la venida de Elías, la Escritura ya se cumplió, pues Elías vino (Juan Bautista) y los dirigentes de Israel han hecho con él lo que han querido.

La tercera razón es la opción textual que presenta el Códice Beza (D), del siglo V, que lee en Marcos 9,12: «Si cuando Elías venga restaura todas la cosas, entonces, ¿cómo es que se ha escrito del Hijo del hombre...». Ahora bien, sin ser un códice del todo confiable, da la impresión de que aquí podría expresar el sentido pretendido por Marcos.

- Varios aspectos literarios de la traducción entre, por un lado, Bover - O'Callaghan y las traducciones de equivalencia formal y, por otro, la $B L A$ son distintos. Ello responde al deseo de la $B I A$ de expresar los significados genuinos del sentido literal (contenido) en un código de signos (castellano como lenguaje) y en un canal de comunicación (un escrito literariamente de calidad) comprensible para el lector de hoy, permitiendo así que asuma su rol de auténtico lector-receptor e interlocutor.

\section{Conclusion:}

Si preguntamos qué traducción se ajusta mejor al texto griego del Textus Receptus, la respuesta es obvia: la de Bover - O'Callaghan y, además, todas aquellas Biblias que buscan una traducción literalista. Pero si preguntamos qué traducción busca expresar los significados

40 Cfr. Zerwick (1997: $\mathrm{n}^{\circ}$ 222): hóti de Mc 9,11 podría estar en lugar de tí (= día tî) con el significado de así que..., entonces por qué... (pregunta); Bratcher \& Nida, 1961: 279281; Gnilka, 1986: II 45-49; Taylor, 1979: 469-470; Trocmé, 2000: 238-241; Mateos \& Camacho, 1993 y 2008: 325-329; Marcus, 2011: II 737-740.

41 Cfr. Justino Mártir, Diálogo con Trifón, 49,1. También la comunidad de Qumrán esperaba la venida de un Profeta y de un Mesías de Aarón y de Israel. 
consignados en el textus, haciéndolos comprensibles al lector de hoy, me parece que la respuesta también es obvia: la $B I A$ y aquellas Biblias preocupados por trasvasar el mensaje del Nuevo Testamento al destinatario de hoy ${ }^{42}$.

Quizás esta concreta propuesta de traducción de la $B L A$ no sea la mejor en vista a explicitar el mensaje, pues podrían formularse otras propuestas mejores; sin embargo, estoy convencido de que este intento es el camino a seguir si queremos que la Sagrada Escritura sea mediación de revelación del misterio de Dios y lugar teológico de encuentro personal con Él.

Sólo así se vivirá dentro de la Palabra, «para dejarse proteger y alimentar como en un regazo materno» ${ }^{43}$.

\section{REFERENCIAS}

-Alonso Schökel, L. (Dir.). (1969). Comentarios a la constitución Dei Verbum sobre la divina revelación. Madrid: Biblioteca de Autores Cristianos.

-Alonso Schökel, L. (1986). Hermenéutica de la palabra. (Vol. I). Madrid: Cristiandad.

-Alonso Schökel \& Zurro, E. (1977). La traducción biblica: lingüística y estilistica. Madrid: Cristiandad.

-Bover, J. M. \& O’Callaghan (1977): Nuevo Testamento Trilingüe (Edición crítica). Madrid: Biblioteca de Autores Cristianos.

-Bratcher, R. G. \& Nida, E. A. (1961). The Gospel of Mark. New York: USB Handbook Series.

-Castaño Fonseca, A. (1997). Dikaiosyne en Mateo. Una interpretación teológica a partir de 3,15 y 21,32. Roma: Editorial Pontificia Universitá Gregoriana.

-Dias da Silva, C. M. (2000). Metodologia de exegese bíblica. São Paulo: Paulinas.

-Egger, W. (1990). Lecturas del Nuevo Testamento. Metodología lingüistica históricocrítica. Estella (Navarra): Verbo Divino.

-García, A. (2011). Diccionario del Griego Bíblico. Setenta y Nuevo Testamento. Estella (Navarra): Verbo Divino.

-Gnilka, J. (1986). El Evangelio segín san Marcos (2 Vols.). Salamanca: Sígueme.

-Guijarro, S. (2010). Los Cuatro Evangelios. Salamanca: Sígueme.

-Huning, R. (2007). Aprendiendo de Carlos Mesters: hacia una teoría de lectura bíblica. Estella (Navarra): Verbo Divino.

-Junco Garza, C. (2008a). La Biblia, libro sagrado. Estella (Navarra): Editorial.

-Junco Garza, C. (2008b). Génesis de la "Dei Verbum” y puntos controvertidos en que intervino el Papa. Asociación Biblistas Mexicanos, 17, 9-26.

42 Así la Biblia de América, Biblia del Pueblo de Dios, La Biblia de nuestro pueblo, y otras varias.

43 Juan Pablo II, Pastores gregis, n 15. 
-Junco Garza, C. (2008c). La interpretación de la Escritura. Análisis de DV 12 y grandes líneas de La Interpretación de la Biblia en la Iglesia (PCB 1993). Asociación Biblistas Mexicanos, 17, 27-48.

-Lapide, P. (2000). Bibbia tradotta, Bibbia tradita. Bologna: EDB.

-Lugo, R. (2008). Ojos del mundo, ojos de Dios. La comunidad cristiana como espacio interpretativo. Asociación Biblistas Mexicanos, 17, 65-80.

-Maggioni, B. (1990). Exégesis bíblica. En P. Rossano, G. Ravasi \& A. Girlanda (Dirs.), Nuevo Diccionario de Teología Bíblica (págs. 620-632). Madrid: Paulinas.

-Marcus, J. (2011). El Evangelio según Marcos (2 Vols.). Salamanca: Editorial.

-Margot, J.-C. (1987). Traducir sin traicionar. Teoría de la traducción aplicada a los textos biblicos, Madrid: Cristiandad.

-Martínez, J. M. (1984). Hermenéutica biblica. Barcelona: CLIE.

-Mateos, J. \& Camacho, F. (1993). El Evangelio de Marcos. Análisis lingüistico y comentario exegético (Vol. I). Madrid: Editorial El Almendro.

-Mateos, J. \& Camacho, F. (2000). El Evangelio de Marcos. Análisis lingüistico y comentario exegético (Vol. II). Madrid: Editorial El Almendro.

-Mateos, J. \& Camacho, F. (2008). El Evangelio de Marcos. Análisis lingüistico y comentario exegético (Vol. III). Madrid: Editorial El Almendro.

-Nida, E. A. \& Taber, Ch. R. (1986). La traducción: teoría y práctica, Madrid: Cristiandad.

-Nida, E. A. \& Reyburn, W. D. (2011). Significado y diversidad cultural. Miami: Soc. Bíblicas Unidas.

-Ortíz, P. (2003). Introducción a los Evangelios. Bogotá: Pontificia Universidad Javeriana.

-O'Callaghan, J. (1982). El Nuevo Testamento en las versiones españolas. Rome: Biblical Institute (Subsidia Biblica, 6).

-Paglia, V. (Dir.) (2008). La Sete della Parola. Indagine Internazionale sulla lettura della Scrittura. Roma: FEBIC.

-Parmentier, E. (2007). La Scrittura viva. Guida alle interpretazioni cristiane della Bibbia. Bologna: EDB.

-Passoni Dell'Acqua, A. (1994). Il Testo del Nuovo Testamento. Introduzione alla critica testuale. Torino: Elle Di Ci.

-Pié-Ninot, S. (2006). La teología fundamental (Sexta Edición). Salamanca: Sec. Trinitario.

-Schrenk, G. (1966). dikaiosýne y dikaíosis. En G. Kittel \& G. Friedrich, Grande lessico del Nuovo Testamento. (Vol. II). Brescia: Paideia.

-Silva Retamales, S. (1997). Lenguaje, exégesis y hermenéutica. En El quehacer teológico. Experiencia, lenguaje y comunicación de la fe (págs. 195-248). Santiago de Chile: Sociedad Chilena de Teología.

-Silva Retamales, S. (2012). La Palabra de Dios, el corazón de toda actividad eclesial. Una presentación de Verbum Domini. Bogotá, D.C.: San Pablo-CELAM.

-Silva Retamales, S. \& Junco Garza, C. (2011). Historia y principios hermenéuticos en la nueva traducción Biblia de la Iglesia en América (BLA). En S. Guijarro \& G. Hernández (Coords.), Los ecos de la Escritura. Homenaje a José Manuel Sánchez Caro (págs. 197-214). Estella (Navarra): Verbo Divino. 
-Taylor, V. (1979). Evangelio según san Marcos. Madrid: Herder.

-Trocmé, E. (2000). L'Évangile selon saint Marc. Genève: Labor et Fides.

-Zerwick, M. (1997). El Griego del Nuevo Testamento. Estella (Navarra): Verbo Divino.

Sumario: 1. Propósito; 2. La revelación y la función de la Sagrada Escritura; 3. La Palabra de Dios en el textus bíblico; 4. Algunos desafíos en la traducción de la Sagrada Escritura; 5. Hermenéuticas para una buena traducción de la Sagrada Escritura; 6. Fidelidades para una buena traducción de las Escrituras; 7. Traducir, para encontrar la Palabra de Dios en las Escrituras; 8. Ejemplos de traducción de los Evangelios de la BLA; Referencias. 